IZA DP No. 6550

Human Capital, Economic Growth, and Inequality in China

James J. Heckman

Junjian Yi

May 2012 


\title{
Human Capital, Economic Growth, and Inequality in China
}

\author{
James J. Heckman \\ University of Chicago \\ and IZA \\ Junjian Yi \\ University of Chicago
}

\section{Discussion Paper No. 6550 \\ May 2012}

\section{IZA}
P.O. Box 7240
53072 Bonn
Germany

Phone: +49-228-3894-0

Fax: +49-228-3894-180

E-mail: iza@iza.org

\begin{abstract}
Any opinions expressed here are those of the author(s) and not those of IZA. Research published in this series may include views on policy, but the institute itself takes no institutional policy positions.

The Institute for the Study of Labor (IZA) in Bonn is a local and virtual international research center and a place of communication between science, politics and business. IZA is an independent nonprofit organization supported by Deutsche Post Foundation. The center is associated with the University of Bonn and offers a stimulating research environment through its international network, workshops and conferences, data service, project support, research visits and doctoral program. IZA engages in (i) original and internationally competitive research in all fields of labor economics, (ii) development of policy concepts, and (iii) dissemination of research results and concepts to the interested public.
\end{abstract}

IZA Discussion Papers often represent preliminary work and are circulated to encourage discussion. Citation of such a paper should account for its provisional character. A revised version may be available directly from the author. 
IZA Discussion Paper No. 6550

May 2012

\begin{abstract}

\section{Human Capital, Economic Growth, and Inequality in China}

China's rapid growth was fueled by substantial physical capital investments applied to a large stock of medium-skill labor acquired before economic reforms began. As development proceeded, the demand for high-skill labor has grown, and, in the past decade, China has made substantial investments in producing it. The egalitarian access to medium-skill education characteristic of the pre-reform era has given rise to substantial inequality in access to higher levels of education. China's growth will be fostered by expanding access to all levels of education, reducing impediments to labor mobility, and expanding the private sector.
\end{abstract}

JEL Classification: $\quad$ I25, J24, O15

Keywords: education, human capital, economic growth, inequality

Corresponding author:

James J. Heckman

Department of Economics

University of Chicago

1126 East 59th Street

Chicago, IL 60637

USA

E-mail: jjh@uchicago.edu 
China's rapid growth in the past 30 years was fueled by substantial physical capital investments applied to a large stock of medium-skill labor acquired before economic reforms began. ${ }^{1,2}$ As development proceeded, the demand for high-skill labor grew, and in the past decade China has made substantial investments in producing it. The egalitarian access to medium-skill education characteristic of the pre-reform era has given rise to substantial inequality in access to higher levels of education. China's growth will be fostered by expanding access to all levels of education, reducing impediments to labor mobility, and expanding the private sector.

The complementarity between the abundant medium-skill labor and the large inflow of physical capital induced by the Open Door policy fostered China's economic growth since 1979. The high saving rate, fast accumulation of physical capital, and integration of China into the world economy during the 1980s and 1990s increased the demand for high-skill workers. The return to education increased dramatically. The government implemented a radical expansion of higher education in 1999 in response to the substantial increase in the demand for high-skill labor. As a result, the skill level of the labor force has been substantially increased in the first decade of the $21^{\text {st }}$ century. However, the restrictive household registration (hukou) system and segmented labor market distort the incentives to invest in human capital and have created a large pool of "left behind" children in rural areas. Moreover, reliance on family resources to finance the children's education beyond the primary level, the lack of capital markets, and substantial increases in tuition and accommodation fees have restricted opportunities for children from poor families to attain

\footnotetext{
${ }^{1}$ Medium-skill labor refers to those with primary or secondary education. The illiterate or semi-illiterate are referred to as low-skill labor. The tertiary education graduates are defined as high-skill labor.

${ }^{2}$ For an insightful discussion of China's economic reforms and its policies, see Lin (2011).
} 
higher education. These factors reduce social mobility and perpetuate intergenerational poverty.

\section{Complementarity between abundant medium-skill labor and the large inflow of physical capital initiated China's economic growth since 1979}

The extraordinarily high primary and middle school enrollment rates before the 1979 economic reform have not been fully appreciated in the literature studying China's economic growth. For example, in 1975 the primary school enrollment rate was 96\%, and the middle school enrollment rate was $60 \%$ (NBS, 2010). Adjusting for stages of economic development, the primary and secondary enrollment rates were much higher in China than in other Asian countries, such as South Korea and Taiwan, during the early stage of their economic take-off (Becker et al., 2012). Further, the Chinese pupil-teacher ratio of primary school in 1976 was 29, ranking 51st in the world and second in South and East Asia, next to Japan (World Bank, 2011).

However, in 1976, per capita GDP in China was about $2 \%$ of that in the U.S., ranking near the bottom of the world. In contrast with the abundance of labor, physical capital was extremely scarce in the 1970s. For example, the net foreign exchange reserve was a negligible 0.58 billion U.S. dollars in China in 1976 (NBS, 2010). The Open Door policy induced a huge inflow of physical capital since 1979. The total amount of FDI was US\$1,096.6 billion from 1979 to 2008

(NBS, 2010). The per capita FDI was higher in China than in South Korea and Taiwan at the same stage of economic development. 


\section{Fast accumulation of physical capital increased the demand for higher education}

However, the stock of high-skill labor was low. Tertiary education was suspended during the Cultural Revolution from 1966 to 1976 . Tertiary school enrollment rates hovered around $1.5 \%$ to 2.5\% from 1979 to 1995 (NBS, 2011a). With economic growth and fast accumulation of physical capital, the return to education increased (Wang, 2012). China, like other East Asian countries, maintained a national gross saving rate as high as $35-55 \%$ throughout the entire economic reform period, dramatically increasing the marginal productivity of labor, especially high-skill labor. The newer technology was strongly complementary with high-skill labor (Liang, 2012).

The increase in the demand for higher education led the government in 1999 to implement a radical policy expansion of higher education. The total number of fresh college graduates increased more than six-fold from 960,000 in 2001 to 6,350,000 in 2010, at an annual increment of 1 million per year (NBS, 2011a). The tertiary school enrollment rates jumped from less than $3 \%$ to almost $19 \%$ during the same period. Moreover, the increase in the stock of domestic college graduates is only a part of the entire picture. Constant et al. (2011) show that the number of Chinese students studying abroad also increased dramatically. In 2000, less than 40,000 Chinese students went overseas. This number increased more than four-fold to almost 180,000 in 2008 . China's impressive strides in human capital investment and its notable achievements in education have not been fully appreciated in the scholarly literature. 


\section{Widening inequality in education in China}

Along with the rapid economic growth and expansion in higher education, inequality in education in China increased drastically. Public schooling is funded mainly at the local level. Rich provinces tend to produce more human capital per capita than poor provinces. Resource constraints differentially affect the access to schooling of individuals in different segments of Chinese society. Particularly hard hit are children in rural areas and those in the West. The place of birth is now one of the most important determinants of adult skill levels (Fleisher et al., 2011), creating serious regional disparities. Place of birth is an important source of cross-sectional and intergenerational inequality in Chinese society (Heckman, 2003, 2005).

This inequality is reinforced by the hukou system. Data from the $1 \%$ sample of the 2005 Census show that there are about 140 million rural-to-urban migrants working in urban areas. Most of these migrants are not able to acquire urban residency due to the hukou system. Most children of these migrants are deprived of the right to attend free public schools in urban areas. Those able to attend public schools in the city have to pay a substantial tuition fee above what is required of locals. As a consequence, many migrant workers leave their school-age children behind to attend schools in their home villages. These "left-behind" children are usually cared for by grandparents or other relatives. According to the research commissioned by the All-China Federation of Women, the estimated number of left-behind children is 58 million (Ye et al., 2005). The rapid increase in the number of left-behind children causes serious concerns for Chinese society. The quality of schooling received by these children is not the only source of concern. The substantially negative 
effect on the children's psychological development and human capital caused by the parental absence is another serious issue. The hukou system has produced a segmented labor market (Fleisher and Wang, 2004; Meng and Zhang, 2001). In this system, the hukou status is a major determinant of an individual's salary, which distorts incentives to invest in human capital (Heckman, 2005).

The ratio of government investment in schooling over GDP has historically been very low, and was $3 \%$ in 2007, despite the fact that tertiary school enrollment rates increased from less than $2 \%$ in 1990 to almost $19 \%$ in 2010 . Tertiary education in China is mainly financed by a child's family. In addition, tuition fees have also increased substantially with the rapid expansion of higher education. In the early 1990s, higher education was almost entirely subsidized by the government. However, tuition fees plus accommodation fees for an ordinary college student exceeded RMB10,000 per year in 2010. Since the annual income for rural residents is only RMB5,919, and the annual disposable income for urban residents is RMB19,109 in the same year (NBS, 2011b), the cost of attending colleges has become a heavy burden for ordinary families, particularly for rural families. The lack of any capital market to finance the college education of children has exacerbated inequality in education. Li and Xing (2010) find that, relative to other groups, minority females and children from the central-western region and rural areas are much less likely to enter college. Wang et al. (2007) report evidence of the growing influence of private financial constraints on decisions to attend college as tuition costs have risen. Educational reforms without concomitant capital market reforms or government support for the financially disadvantaged further contribute to the increase in inequality. 
In addition, educational choice is a sequential process. The increase in the cost of attending tertiary schools discourages children from poor and rural families from attending secondary school because the option value of attending secondary school has decreased. In recent years, secondary school enrollment in rural areas has deteriorated (NBS, 2011a).

\section{Promoting human capital, economic growth, and reducing inequality}

Although notable achievements in education have been made in the past decades, China still faces serious challenges in decreasing inequality in education, fostering a high-skill workforce and promoting economic growth.

Given the current stock of the high-skill workers, the returns to additional government expenditures on education are very high. From this perspective, the current practice of having tertiary education financed mainly by families is both inefficient and inequitable. Investment in human capital has strong positive external effects on society. The absence of capital markets limits access to schooling. Relying on family resources to finance a child's education creates persistent intergenerational poverty.

Policies that balance and expand human capital investment across geographic regions and across rural vs. urban areas, and policies that build more primary and secondary schools in urban areas to accommodate migrant children promote efficiency and reduce inequality. Expanding the college loan system will allow students to borrow against their future earnings. This would allow children from poor families to have the opportunity to pursue higher education (Heckman, 2005). 
Increasing government expenditure is not the only way to enhance the quality of education. A lesson learned from studies in the United States, Europe, and other countries around the world is that competition among schools provides incentives for improving the performance of educational institutions (Heckman, 2000). Allowing more private and foreign educational organizations to operate promotes competition between public and private schools and enhances the resources available to support the expansion of education. Even if the government is cautious in permitting private and foreign educational institutions to enter the market, allowing more competition among existing public schools will promote the quality of education.

Freeing up the labor market is another way to foster human capital development with little direct cost to the government. The segmented labor market produced by the hukou system reduces incentives to invest in human capital in China. Current practices restrict labor mobility across regions. A free labor market allows individuals to reap the fruits of their skills and allows the forces of market incentives to operate.

\section{Summary}

China's rapid economic growth was initiated by the complementarity between a solid base of medium-skill labor and a huge inflow of FDI. It has been sustained by rapid physical capital accumulation and human capital formation. However, China is now facing serious challenges in the areas of education, the quality of its labor force, and in sustaining its economic growth. These challenges can be met by equalizing access to education, reducing restrictions on mobility, and creating effective markets to finance human capital. 


\section{References}

Becker, G., K. Ye, and J. Yi (2012). Rapidly growing human capital investment in China. Unpublished manuscript, Department of Economics, University of Chicago.

Constant, A., J. Meng, B. Tien, and K. Zimmermann (2011). China's latent human capital investment: Achieving milestones and competing for the top. IZA Discussion Paper, No.5650.

Fleisher, B., H. Li, and M. Q. Zhao (2011). Human capital, economic growth, and regional inequality in China. Journal of Development Economics 92 (2), 215-31.

Fleisher, B. M. and X. Wang (2004,). Skill differentials, return to schooling, and market segmentation in a transition economy: The case of mainland China. Journal of Development Economics 73 (1), 315-328.

Heckman, J. J. (2000). Policies to foster human capital. Research in Economics 54 (1), 3-56.

Heckman, J. J. (2003). China's investment in human capital. Economic Development and Cultural Change 51 (4), 795-804.

Heckman, J. J. (2005). China's human capital investment. China Economic Review 16 (1), 50-70.

Li, S. and C. Xing (2010). China's higher education expansion and its labor market consequences. IZA Discussion Papers 4974.

Liang, J. (2012). Evolution of the labor market in a rapidly developing economy. Unpublished manuscript, Graduate School of Business, Stanford University.

Lin, J. Y. (2011). Demystifying the Chinese economy. Cambridge: Cambridge University Press.

Meng, X. and J. Zhang (2001). The two-tier labor market in urban China: Occupational segregation and wage differentials between urban residents and rural migrants in Shanghai. Journal of Comparative Economics 29 (3), 485-504.

National Bureau of Statistics (2010). China Compendium of Statistics 1949-2008. Beijing: China Statistics Press.

National Bureau of Statistics (2011a). China Education Yearbook. Beijing: China Statistics Press.

National Bureau of Statistics (2011b). China Statistics Yearbook. Beijing: China Statistics Press.

Wang, L. (2012). How does education affect the earnings distribution in urban China 1995-2002? Forthcoming, Oxford Bulletin of Economics and Statistics. 
Wang, X., B. M. Fleisher, H. Li, and S. Li (2007). Access to higher education and inequality: The Chinese experiment. IZA Discussion Papers, 2823.

World Bank (2011). World Bank Data Catalog. http://data.worldbank.org/indicator.

Ye, J., J. Murray, and Y. Wang (2005). Left-behind Children in Rural China: Impact Study of Rural Labor Migration on Left-behind Children in Mid-West China. Beijing: Social Sciences Academic Press. 